\title{
Perceived Institutional Obstacles in Doing Business: A Comparative Study of South Africa and The Philippines
}

\section{Mary Jesselyn Co}

\author{
School of Economics and Management, University of Kwazulu-Natal
}

\begin{abstract}
There is ample evidence indicating that institutional environments have a direct effect on the performance of small enterprises. Furthermore, perceptions of how the institutional environment will hinder or foster their respective firms shape the actions entrepreneurs take. This research investigates whether there are differences between South African and Filipino entrepreneurs in their perceptions of institutional obstacles in doing business - specifically the government-business interface. A sample size of 615 small and medium sized firm owners from different industries from both countries were provided with a list of 15 areas where the firm is confronted with government action and were asked to evaluate the degree to which these different areas create obstacles for conducting business. A discussion of the overall findings, as well as applicable lessons and future research follows.
\end{abstract}

JEL E31, 37, 52

\section{INTRODUCTION}

There is strong evidence that supports the belief that productive entrepreneurship is an essential explanatory factor for the economic performance of a country, and hence that cross-country differences in the degree of productive entrepreneurial activity are partial explanatory factors of observed cross-country differences in economic performance (Davidsson \& Henrekson, 2000). The promotion of SMEs has become an important strategy for economic development for most countries. It is interesting to note that despite differences in the institutional environments, entrepreneurs still flourish. In developing countries such as South Africa and The Philippines, rates of business start-ups have increased, which is despite the difficulties in finding financing, high tax regulations, inflation, crime and theft and corruption. 
Attitudes towards smaller businesses and entrepreneurial start-ups appear to be shifting favourably among political and economic decision-makers as the evidence of their importance mounts (Lundstrom \& Stevenson, 2001). The role of the government in the development and growth of SMEs cannot be underemphasised. The government's role in encouraging entrepreneurship is not just limited to providing a stable political scene and an institutional environment conducive for business. To stimulate economic growth through entrepreneurship, the government must provide the right combination of policies and incentives to attract individuals to become entrepreneurs.

In identifying key institutional determinants of firm emergence and growth, Davidsson and Henrekson (2000) analysed a number of institutions and policy measures that are likely to have contributed to an environment that discourages firm activity and growth. The aspects dealt with included: the lack of entrepreneurship in the care sectors and household related services, taxation of entrepreneurial income, incentives for wealth accumulation, wage-setting institutions and labour market regulations. The investigation provided evidence of a low prevalence of nascent entrepreneurs and a small employment contribution by high growth firms. Among the high growth firms that existed in 1987 either as independent companies or as SME company groups, and which still existed as independent entities in 1996, the most spectacular growth case added 596 new jobs. Only fourteen cases added more than 250 jobs each; collectively these fourteen cases added 5217 new jobs over the ten-year period. This represents close to a complete void of spectacular high growth firms.

Entrepreneurs may be discouraged from starting a business if they have to adhere to an excessive number of rules and procedures. The level of procedural requirements for registration and licensing, taxes, and financial reporting may either facilitate or hinder entrepreneurial activities. Research shows that most small businesses consider paperwork very time consuming and cumbersome (Dana, 1987, 1990; Young \& Welsch, 1993; Fogel, 1994). Countries that keep procedural requirements to a minimum generally have a viable and dynamic entrepreneurial sector. Research also shows that tax and other start-up incentives have a positive impact on small business establishments and growth (Davidsson \& Henrekson, 2000).

In a worldwide study of institutional environments, a World Bank policy team (Brunetti, Kisunko \& Weder, 1997) surveyed more than 3,600 entrepreneurs from 69 countries and developed five quantitative indicators of institutional uncertainty: predictability of laws and policies, reliability of the judiciary, political stability, corruption in bureaucracies, and security of property rights. They found that uncertainty about policies, laws and regulations has hampered development of the private sector in many developing countries. 
The above-mentioned investigation has motivated this research. The main purpose of this study is to describe and compare the perceived institutional obstacles affecting entrepreneurs in South Africa and The Philippines. The index developed in the World Bank Report on the overall government-business interface as perceived by entrepreneurs themselves shall be the focus of this paper.

\section{PROBLEM STATEMENT}

This paper primarily focuses on the perceptions of the entrepreneurs on various obstacles in doing business. They consist of the following items: start-up regulations, price controls, foreign trade regulations, financing, labour regulations, foreign currency regulations, tax regulations, inadequate infrastructure supply, policy instability, safety/environmental regulations, inflation, general uncertainty on cost of regulations, crime and theft, corruption and terrorism. This research will compare the perceptions of entrepreneurs from South Africa and The Philippines as well as from less developed countries (LDC), sub-Saharan Africa (SSA) and the overall World Bank findings.

To date, very few studies have evaluated the institutional environment surrounding SMEs. Even rarer are cross-country comparisons of institutional environments affecting small businesses. Cross-country comparisons would give more insight into how differences in context would affect the conduciveness of a country towards entrepreneurship. This type of investigation will also present similarities and differences in the perceptions of entrepreneurs from different countries, regardless of the context. It is also important to note that in this study, the entrepreneurs themselves evaluated the institutional environment. In order to be effective in promoting and developing SMEs, it is important to evaluate the institutional environment from the point of view of the main actor - the entrepreneur.

\section{THEORETICAL BACKGROUND}

Institutional theory is the theoretical framework used in this study. This theory developed by developed by Douglass C. North, primarily analyses economic structures by explaining how institutions and institutional changes affect the performance of economies. Veciana (1999) stated, "Without doubt the theory that currently supplies the most consistent and appropriate conceptual framework to probe the influence of environmental factors on entrepreneurship is institutional theory." 
Institutions, according to North (1989: 238), which arise because of the uncertainty associated with human interaction, provide structure and order, the rules of the game to human exchange, whether political, social or economic. It provides the framework, the structure, to facilitate certain kinds of exchange as well as a framework within which people have some confidence as to how outcomes will be determined. They consist of both formal and informal constraints as well as their enforcement characteristics.

Informal constraints include norms, codes of behaviour, subjective perceptions and traits. They arise to coordinate repeated human interaction and these constraints are extensions, elaborations, and modifications of formal rules, social sanctions and internally enforced standards of conduct. Formal constraints on the other hand include political (and judicial) rules, economic rules, and contracts (North, 1991: 47). The function of these rules is to facilitate political or economic exchange. Enforcement on the other hand refers to whether the rules and informal constraints are enforced (and how rigidly it is enforced) or not enforced.

Using North's institutional theory, the perceived overall government-business interface has an effect on the entrepreneurs' perceptions of conduciveness of the environment for business. If entrepreneurs perceive the obstacles as being problematic, this hampers development of the private sector. Therefore, individuals tend to feel discouraged in pursuing entrepreneurial endeavors.

This study will only focus on the formal institutional factors specifically the government-business interface. Other aspects such as informal and enforcement factors will be dealt with in a forthcoming paper.

\section{METHODOLOGY}

\section{Sample}

The total sample consisted of 615 randomly selected entrepreneurs from the cities of Durban and Manila. Firms that had an employment size of 10-199 (for The Philippines) and 10-100 (for South Africa) employees served as respondents. Only the following four industry sectors were included in the survey of entrepreneurs: manufacturing; wholesale and retail; finance, real estate, insurance and business services; as well as community, social and personal services. Almost 90 per cent of all SMEs in Durban and Manila are from these industry sectors. Table 1 shows the breakdown of the sample by industry and size of the firm. 
Table 1 Breakdown of sample by industry and size of the firm

\begin{tabular}{|l|c|c|c|c|}
\hline & \multicolumn{2}{|c|}{ South Africa } & \multicolumn{2}{c|}{ The Philippines } \\
\hline Industry & $\mathbf{N}$ & $\mathbf{\%}$ & $\mathbf{N}$ & $\mathbf{\%}$ \\
\hline Manufacturing & 75 & 23.08 & 58 & 20.00 \\
\hline Wholesale and retail & 113 & 34.77 & 105 & 36.20 \\
\hline $\begin{array}{l}\text { Finance, real estate, insurance and } \\
\text { business services }\end{array}$ & 53 & 16.30 & 55 & 18.97 \\
\hline Community, social and personal services & 84 & 25.85 & 72 & 24.83 \\
\hline Employment size & & & & \\
\hline Small & 299 & 92.00 & 247 & 85.17 \\
\hline Medium & 26 & 8.00 & 43 & 14.83 \\
\hline
\end{tabular}

\section{Instrumentation}

The complete questionnaire contained 25 questions. They were from a World Bank survey questionnaire conducted by Brunetti, Kisunko and Weder (1997). The researcher obtained permission to use the questionnaire from the authors. This paper will deal with only one aspect of institutional obstacles specifically the government-business interface. This section provided the respondent with a list of 15 areas where the firm encounters government action and asks the owner to evaluate the degree to which these different areas create obstacles for doing business. The questionnaire used a Likert scale of six choices. The answers for the questions ranged from one (not a problem) to six (very strong problem) with the option of answering zero if the question was not applicable to the respondent or where there was no response.

\section{Data gathering procedure}

Use was made of research assistants, who after instruction learned how to distribute and collect the questionnaire. Each research assistant distributed the questionnaire to several assigned firms. They emphasized that only the entrepreneurs themselves should answer the questionnaires. They then collected the completed questionnaire the following day. Before leaving the premises of the firm, the research assistant ensured the completion of all questions. This method of data collection ensured a higher response rate.

\section{Data analysis}

The data analysis in this study includes descriptive statistics such as means, frequencies and cross-tabulations. The index of obstacles for doing business on the other hand, takes the mean scores of the sample's responses on each of the 
15 items. In determining differences between South African and Philippine entrepreneurs, t-tests measure differences between means of the obstacles while chi-squares $\left(\chi^{2}\right)$ indicate differences in the percentages of perceived problematic obstacles. The analysis also compares the results of the South African and Philippine sample with the results obtained by Brunetti, Kisunko and Weder's (1997) study on world, less developed countries (LDCs) and subSaharan Africa countries (SSAs)

\section{RESULTS}

Table 2 presents the comparative index of obstacles for doing business.

Table 2 Comparative index of obstacles for doing business

\begin{tabular}{|l|c|c|c|c|c|c|}
\hline \multicolumn{1}{|c|}{ Obstacles } & SA & Phil & World & LDC & SSA & $\begin{array}{c}\text { t-test } \\
\text { value }\end{array}$ \\
\hline Start-up regulations & 2.48 & 3.69 & 3.22 & 3.19 & 3.24 & $-10.016^{*}$ \\
\hline Price controls & 2.76 & 3.75 & 2.67 & 2.72 & 2.63 & $-8.214^{*}$ \\
\hline Foreign trade regulations & 2.84 & 4.07 & 3.45 & 3.57 & 3.57 & $-10.038^{*}$ \\
\hline Financing & 2.87 & 4.04 & 4.06 & 4.18 & 4.17 & $-9.838^{*}$ \\
\hline Labour regulations & 3.23 & 4.12 & 3.50 & 3.39 & 3.47 & $-7.298^{*}$ \\
\hline Foreign currency regulations & 2.71 & 4.16 & 3.16 & 3.32 & 3.47 & $-11.105^{*}$ \\
\hline Tax regulations/high taxes & 3.59 & 4.67 & 4.65 & 4.72 & 4.65 & $-9.146^{*}$ \\
\hline Inadequate infrastructure supply & 2.58 & 3.92 & 4.02 & 4.16 & 4.31 & $-11.472^{*}$ \\
\hline Policy instability & 2.52 & 4.07 & 3.68 & 3.88 & 3.63 & $-13.584^{*}$ \\
\hline Safety/environment regulations & 2.85 & 3.90 & 3.24 & 3.21 & 3.36 & $-8.990^{*}$ \\
\hline Inflation & 3.65 & 4.51 & 3.82 & 4.06 & 4.30 & $-7.258^{*}$ \\
\hline $\begin{array}{l}\text { General uncertainty on cost of } \\
\text { regulations }\end{array}$ & 2.91 & 4.02 & 3.75 & 3.86 & 3.84 & $-9.480^{*}$ \\
\hline Crime and theft & 3.95 & 4.49 & 3.88 & 4.17 & 4.27 & $-4.050^{*}$ \\
\hline Corruption & 3.15 & 4.65 & 4.21 & 4.45 & 4.67 & $-10.727^{*}$ \\
\hline Terrorism & 2.47 & 4.07 & 2.38 & 2.45 & 2.28 & $-11.515^{*}$ \\
\hline
\end{tabular}

*significant at $\rho \leq 0.05$

The findings in table 2 indicate that there are significant differences (based on ttest results) in how South African and Philippine entrepreneurs view the various obstacles for doing business. At 14 degrees of freedom and $\rho \leq 0.05$, the critical value from the $\chi^{2}$ table is 6.571 .

On all types of obstacles, the South African entrepreneurs perceived them as less problematic than their Philippine counterparts. All of the mean responses 
of the South African entrepreneurs are between 2.5 to 4 (out of a scale of 1 to 6), which is between the not problematic to moderately problematic scale. The Philippine respondents on the other hand have scores ranging from 3.69 to 4.75, which indicate a scale between moderately problematic to very problematic. South African entrepreneurs generally perceive their obstacles as less problematic even when compared to the world, LDCs and SSAs in all instances except price control, terrorism and crime and theft (only when compared to world figures). Philippine entrepreneurs on the other hand have higher indices when compared to the world, LDCs and SSA countries except in the inadequacy of infrastructure supply, financing, crime and theft, corruption (SSAs), and taxation (LDCs).

Table 3 presents the percentage of the respondents that perceive the various obstacles as being problematic, that is, they indicated a response of 4 to 6 in the scale. Results show that based on the chi-square tests, there are significant differences between the South African and Philippine respondents. At 14 degrees of freedom and $\rho \leq 0.05$, the critical value from the t-test table is 2.145 .

Table 3 Perceived problematic obstacles (comparative percentages)

\begin{tabular}{|l|c|c|c|c|c|c|}
\hline \multicolumn{1}{|c|}{ Obstacles } & SA & Phil & World & LDC & SSA & $\chi 2$ value \\
\hline Start-up regulations & 21.00 & 58.50 & 38 & 37 & 37 & $127.470^{*}$ \\
\hline Price controls & 27.85 & 58.09 & 26 & 29 & 26 & $75.489^{*}$ \\
\hline Foreign trade regulations & 30.35 & 66.54 & 44 & 47 & 46 & $99.715^{*}$ \\
\hline Financing & 30.26 & 70.11 & 62 & 64 & 62 & $118.593^{*}$ \\
\hline Labour regulations & 42.24 & 71.54 & 46 & 42 & 44 & $68.192 /^{*}$ \\
\hline Foreign currency regulations & 31.77 & 68.18 & 38 & 41 & 45 & $119.685^{*}$ \\
\hline Tax regulations/high taxes & 51.89 & 82.12 & 76 & 79 & 78 & $75.647^{*}$ \\
\hline $\begin{array}{l}\text { Inadequate infrastructure } \\
\text { supply }\end{array}$ & 23.74 & 66.28 & 60 & 65 & 69 & $118.046^{*}$ \\
\hline Policy instability & 22.55 & 69.47 & 52 & 57 & 49 & $148.993^{*}$ \\
\hline $\begin{array}{l}\text { Safety/environment } \\
\text { regulations }\end{array}$ & 30.36 & 69.50 & 38 & 36 & 43 & $115.438^{*}$ \\
\hline Inflation & 57.54 & 79.92 & 55 & 61 & 67 & $58.428^{*}$ \\
\hline $\begin{array}{l}\text { General uncertainty on cost of } \\
\text { regulations }\end{array}$ & 34.91 & 70.27 & 51 & 53 & 51 & $128.740^{*}$ \\
\hline Crime and theft & 58.68 & 80.37 & 57 & 62 & 67 & $66.612^{*}$ \\
\hline Corruption & 41.12 & 79.10 & 65 & 73 & 78 & $103.436^{*}$ \\
\hline Terrorism & 27.86 & 66.15 & 21 & 22 & 19 & $150.302^{*}$ \\
\hline
\end{tabular}

*significant at $\rho \leq 0.05$ 
There were less respondents from South Africa that perceived the various obstacles as problematic when compared to The Philippines, the world, LDCs and SSAs except on terrorism, crime and theft (world), labour regulation (LDCs), and price control (world and SSAs). In contrast, a higher percentage of Filipino entrepreneurs perceived the various obstacles as being problematic when compared to South African entrepreneurs, the world, LDCs and SSAs except in only one obstacle - inadequacy of infrastructure supply (SSAs). This result is consistent with the findings presented in Table 2.

Table 4 presents the various obstacles, as well as how the respondents from the two countries and country groups ranked them. The table also highlights the top five obstacles for each group.

Table 4 Comparative ranking of obstacles

\begin{tabular}{|l|c|c|c|c|c|}
\hline \multicolumn{1}{|c|}{ Obstacles } & SA & Phil & World & LDC & SSA \\
\hline Start-up regulations & 15 & 14 & 12 & 13 & 13 \\
\hline Price controls & 12 & 15 & 14 & 14 & 14 \\
\hline Foreign trade regulations & 9 & 11 & 10 & 9 & 9 \\
\hline Financing & 10 & 7 & 3 & 3 & 6 \\
\hline Labour regulations & 4 & 5 & 9 & 10 & 11 \\
\hline Foreign currency regulations & 7 & 10 & 13 & 11 & 10 \\
\hline Tax regulations/high taxes & 3 & 1 & 1 & 1 & 2 \\
\hline Inadequate infrastructure supply & 13 & 12 & 4 & 5 & 3 \\
\hline Policy instability & 14 & 9 & 8 & 7 & 8 \\
\hline Safety and environment regulations & 8 & 8 & 11 & 12 & 12 \\
\hline Inflation & 2 & 3 & 6 & 6 & 4 \\
\hline $\begin{array}{l}\text { General uncertainty on cost of } \\
\text { regulations }\end{array}$ & 6 & 6 & 7 & 8 & 7 \\
\hline Crime and theft & 1 & 2 & 5 & 4 & 5 \\
\hline Corruption & 5 & 4 & 2 & 2 & 1 \\
\hline Terrorism & 11 & 13 & 15 & 15 & 15 \\
\hline
\end{tabular}

It is interesting to observe that the top five obstacles perceived by both South African and Filipino entrepreneurs are the same - crime and theft, inflation, tax and labour regulations and corruption, although the order of the ranking is slightly different. These obstacles are also among the top five indicated by respondents from the world, LDCs and SSAs except for labour regulations. The world, LDC and SSA respondents indicated that inadequate infrastructure supply is a bigger problem. SSA respondents however also perceive financing as a bigger problem in their country. The rankings of the obstacles also varied considerably between South Africa, Philippines, world, LDCs and SSAs. 


\section{CONCLUSIONS AND RECOMMENDATIONS}

The research results show that entrepreneurs in different countries have similar perceptions of their diverse environment. Entrepreneurs can take comfort that they are not alone in their situation. Entrepreneurs from South Africa ranked the same top five obstacles as their Philippine counterparts. This reinforces the fact that some obstacles encountered by entrepreneurs are universal and are unaffected by the context of each individual country. Furthermore, it is also interesting to note that in both the countries studied most entrepreneurs perceived crime and theft, tax regulations and inflation are the main problematic obstacles entrepreneurs face. As expected there are several aspects where the South African and Philippine entrepreneurs differed (e.g. foreign currency regulations, general uncertainty on cost of regulations, and terrorism). These differences highlight the fact that entrepreneurs in The Philippines encounter more institutional obstacles than in South Africa. In certain aspects, South Africa can be classified as a relatively developed country - its banking system first world, its currency more stable, regulations and policies affecting start-ups more clear cut, better infrastructure, and a more stable economy. The Philippines, on the other hand is still experiencing problems regarding political and economic stability, in addition to inadequate infrastructure supply, plus terrorism down in the southern part of the country. These differences however, do not indicate that the two countries are not comparable. Some contextual problems common to both countries include high unemployment rates, problems with poverty, crime as well as corruption.

Based on the results of the study it is important to point out that there should be an open channel of communication between the entrepreneurs and the government. If the government shows its willingness and sensitivity to hear the entrepreneurs' problems, the more willing the entrepreneurs will be to giving suggestions.

The government must adjust the environment and its policies to make it more conducive to the needs of the entrepreneurs as well as encourage other individuals to follow the entrepreneurial path. The entrepreneurs from both countries have indicated the specific areas they have found problematic and it is now the government's responsibility to improve on these areas of difficulty. Perceptions will improve once entrepreneurs see efforts exerted to alleviate their conditions - this can be in the form of new legislation, reduction of bureaucracy and corruption, information availability, tax incentives, crackdown on crime and theft, and overall improvement in the economic and political stability of the country. 
Cross-country studies like these also help emphasize similarities and differences between countries. The results will indicate necessary policy changes that will help improve the start-up conditions of small firms in similar institutional contexts.

For future research, it would be interesting to relate these perceptions of institutional obstacles to success and/or failure rates of businesses. In addition, it would be noteworthy to study these perceived institutional obstacles and relate them to informal institutional factors (e.g. culture, beliefs and attitudes towards entrepreneurship), and how they can affect enterprise formation.

\section{REFERENCES}

1 BRUNETTI, A., KISUNKO, G., \& WEDER, B. (1997) "Institutional obstacles to doing business: region-by-region results from a worldwide survey of the private sector", World Bank Development Report.

2 DANA, L.P. (1987) "Entrepreneurship and venture creation: an international comparison of five commonwealth nations", Frontiers of Entrepreneurship Research, Babson College: Wellesley, MA.

3 DANA, L.P. (1990) "Saint Martin/Sint Maarten: a case study of the effects of culture on economic development", Journal of Small Business Management, 28(4): 91-98.

4 DAVIDSSON, P. (1991) "Continued entrepreneurship: Ability, need and opportunity as determinants of small firm growth", Journal of Business Venturing, 6(4): 405-29.

5 DAVIDSSON, P. \& HENREKSON, M. (2000) "Institutional determinants of the prevalence of start-ups and high-growth firms: Evidence from Sweden", Paper presented at the Jönköping International Workshop Institutions, Entrepreneurship and Firm Growth, Jönköping, Sweden, January.

6 FOGEL, G. (1994) "Perceptions of small business owners: a study of entrepreneurship in Hungary", Midwest Review of International Business Research, Academy of International Business: 89-99.

7. LUNDSTROM, A. \& STEVENSON, L. (2001) "Entrepreneurship policy for the future", Paper presented at the SME Forum, Stockholm, Sweden, March.

8 NORTH, D. (1991) Institutions, Institutional Change and Economic Performance, Cambridge University Press: New York.

9 NORTH, D. (1989) "Institutional change and economic history", Journal of Institutional and Theoretical Economics, 145(1): 11-23. 
10 VECIANA, J.M. (1999) "Entrepreneurship as a scientific research programme", Revista Europea de Dirrecion y Economía de la Empresa, 8(3): 2-10.

11 YOUNG, E.C. \& WELSCH, H.P. (1993) "Major elements in entrepreneurial development in Mexico", Journal of Small Business Management, 31(3): 80-85. 